\title{
SOME NEW OSTROWSKI AND GRÜSS TYPE INEQUALITIES
}

\|\|

\author{
B. G. PACHPATTE
}

Abstract. In this paper we establish some new inequalities of Ostrowski and Grüss type, involving three functions whose second derivatives are bounded. The analysis used in the proofs is fairly elementary and based on the integral identities for twice differentiable functions.

\section{Introduction}

In 8] A. M. Ostrowski proved the following inequality (see also [7, p.469]).

Let $f:[a, b] \rightarrow R$ be continuous on $[a, b]$ and differentiable on $(a, b)$ whose derivative $f^{\prime}:(a, b) \rightarrow R$ is bounded on $(a, b)$, i.e., $\left\|f^{\prime}\right\|_{\infty}=\sup _{t \in(a, b)}\left|f^{\prime}(t)\right|<\infty$. Then

$$
\left|f(x)-\frac{1}{b-a} \int_{a}^{b} f(t) d t\right| \leq\left[\frac{1}{4}+\frac{\left(x-\frac{a+b}{2}\right)^{2}}{(b-a)^{2}}\right](b-a)\left\|f^{\prime}\right\|_{\infty},
$$

for all $x \in[a, b]$.

In 5] G. Grüss proved the following inequality (see also [6, p.296]).

Let $f, g:[a, b] \rightarrow R$ be two integrable functions such that $p \leq f(x) \leq P$ and $q \leq g(x) \leq Q$ for all $x \in[a, b]$, where $p, P, q, Q$ are constants. Then

$$
\begin{aligned}
& \left|\frac{1}{b-a} \int_{a}^{b} f(x) g(x) d x-\left(\frac{1}{b-a} \int_{a}^{b} f(x) d x\right)\left(\frac{1}{b-a} \int_{a}^{b} g(x) d x\right)\right| \\
& \leq \leq \frac{1}{4}(P-p)(Q-q) .
\end{aligned}
$$

In view of the usefulness of such inequalities in analysis and applications the above inequalities have received considerable attention during the past few years and several studies have been dedicated to obtain various generalizations, extensions and variants, see $[1-4,6,7,9,10]$ and the references given therein. The main objective of the present paper is to establish some new Ostrowski and Grüss type inequalities involving three functions and their first and second order derivatives. The proofs are based on the integral identities established in [1], 2] and [3] for twice differentiable functions.

Received September 20, 2005.

2000 Mathematics Subject Classification. Primary 26D15,41A55.

Key words and phrases. Ostrowski and Grüss type inequalities, twice differentiable functions, integral identities, properties of modulus. 


\section{Statement of Results}

In what follows $R$ and ' denotes the set of real numbers and the derivative of a function and $[a, b]$ for $a<b$ be a given subset of $R$. First we give the following notations used to simplify the details of presentation.

For $x \in[a, b]$ and some suitable functions $f, g, h:[a, b] \rightarrow R$, we set

$$
\begin{aligned}
A[f, g, h](x)= & g(x) h(x) \int_{a}^{b} f(t) d t+h(x) f(x) \int_{a}^{b} g(t) d t+f(x) g(x) \int_{a}^{b} h(t) d t, \\
B[f, g, h](x)= & |g(x)||h(x)|\left\|f^{\prime \prime}\right\|_{\infty}+|h(x)||f(x)|\left\|g^{\prime \prime}\right\|_{\infty}+|f(x)||g(x)|\left\|h^{\prime \prime}\right\|_{\infty}, \\
D[f, g, h]= & \left(\int_{a}^{b} g(x) h(x) d x\right)\left(\int_{a}^{b} f(x) d x\right)+\left(\int_{a}^{b} h(x) f(x) d x\right)\left(\int_{a}^{b} g(x) d x\right) \\
& +\left(\int_{a}^{b} f(x) g(x) d x\right)\left(\int_{a}^{b} h(x) d x\right), \\
L[f, g, h](x)= & g(x) h(x) \frac{f(a)+f(b)}{2}+h(x) f(x) \frac{g(a)+g(b)}{2}+f(x) g(x) \frac{h(a)+h(b)}{2}, \\
M[f, g, h](x)= & g(x) h(x) \frac{f(b)-f(a)}{b-a}+h(x) f(x) \frac{g(b)-g(a)}{b-a}+f(x) g(x) \frac{h(b)-h(a)}{b-a} .
\end{aligned}
$$

Our main results are given in the following theorems.

Theorem 1. Let $f, g, h:[a, b] \rightarrow R$ be twice differentiable functions on $(a, b)$ and $f^{\prime \prime}, g^{\prime \prime}, h^{\prime \prime}:(a, b) \rightarrow R$ are bounded, i.e., $\left\|f^{\prime \prime}\right\|_{\infty}=\sup _{t \in(a, b)}\left|f^{\prime \prime}(t)\right|<\infty,\left\|g^{\prime \prime}\right\|_{\infty}=$ $\sup _{t \in(a, b)}\left|g^{\prime \prime}(t)\right|<\infty,\left\|h^{\prime \prime}\right\|_{\infty}=\sup _{t \in(a, b)}\left|h^{\prime \prime}(t)\right|<\infty$. Then

$$
\begin{aligned}
& \left|f(x) g(x) h(x)-\frac{1}{3(b-a)} A[f, g, h](x)-(f(x) g(x) h(x))^{\prime}\right| \\
& \quad \leq \frac{1}{3(b-a)} B[f, g, h](x) E(x),
\end{aligned}
$$

for all $x \in[a, b]$ and

$$
\begin{aligned}
& \mid \frac{1}{b-a} \int_{a}^{b} f(x) g(x) h(x) d x-\frac{1}{3(b-a)^{2}} D[f, g, h] \\
& \quad-\frac{1}{3(b-a)} \int_{a}^{b}\left(x-\frac{a+b}{2}\right)(f(x) g(x) h(x))^{\prime} d x \mid \\
& \leq \frac{1}{3(b-a)^{2}} \int_{a}^{b} B[f, g, h](x) E(x) d x
\end{aligned}
$$

where

$$
E(x)=\int_{a}^{b}|k(x, t)| d t
$$


in which $k:[a, b]^{2} \rightarrow R$ is given by

$$
k(x, t)=\left\{\begin{array}{l}
\frac{(t-a)^{2}}{2}, t \in[a, x] \\
\frac{(t-b)^{2}}{2}, t \in(x, b]
\end{array}\right.
$$

Remark 1. If we take $h(x)=1$ and hence $h^{\prime}(x)=0, h^{\prime \prime}(x)=0$ in Theorem 1 , then by the elementary calculations we get

$$
\begin{gathered}
\mid f(x) g(x)-\frac{1}{2(b-a)}\left\{g(x) \int_{a}^{b} f(t) d t+f(x) \int_{a}^{b} g(t) d t\right\} \\
\quad-\frac{1}{2}\left(x-\frac{a+b}{2}\right)(f(x) g(x))^{\prime} \mid \\
\leq \frac{1}{2(b-a)}\left\{|g(x)|\left\|f^{\prime \prime}\right\|_{\infty}+|f(x)|\left\|g^{\prime \prime}\right\|_{\infty}\right\} E(x),
\end{gathered}
$$

for all $x \in[a, b]$ and

$$
\begin{gathered}
\mid \frac{1}{b-a} \int_{a}^{b} f(x) g(x) d x-\frac{1}{(b-a)^{2}}\left(\int_{a}^{b} f(x) d x\right)\left(\int_{a}^{b} g(x) d x\right) \\
\quad-\frac{1}{2(b-a)} \int_{a}^{b}\left(x-\frac{a+b}{2}\right)(f(x) g(x))^{\prime} d x \mid \\
\leq \frac{1}{2(b-a)^{2}} \int_{a}^{b}\left\{|g(x)|\left\|f^{\prime \prime}\right\|_{\infty}+|f(x)|\left\|g^{\prime \prime}\right\|_{\infty}\right\} E(x) d x .
\end{gathered}
$$

Further by taking $g(x)=1$ and hence $g^{\prime}(x)=0, g^{\prime \prime}(x)=0$ in (2.5) we get

$$
\left|f(x)-\frac{1}{b-a} \int_{a}^{b} f(t) d t-\left(x-\frac{a+b}{2}\right) f^{\prime}(x)\right| \leq \frac{1}{2(b-a)}\left\|f^{\prime \prime}\right\|_{\infty} E(x) .
$$

We note that the inequalities (2.6) and (2.7) are respectively the same as obtained earlier by Pachpatte in [9] and by Cerone, Drogimir and Roumeliotis in [1].

Theorem 2. Let $f, g, h:[a, b] \rightarrow R$ be functions whose first derivatives are absolutely continuous on $[a, b]$ and assume that the second derivatives $f^{\prime \prime}, g^{\prime \prime}, h^{\prime \prime}:(a, b) \rightarrow R$ are bounded on $(a, b)$. Then

$$
\begin{aligned}
& \left|f(x) g(x) h(x)-\frac{2}{3(b-a)} A[f, g, h](x)-\frac{2}{3}\left(x-\frac{a+b}{2}\right)(f(x) g(x) h(x))^{\prime}+\frac{1}{3} L[f, g, h](x)\right| \\
& \quad \leq \frac{1}{3(b-a)} B[f, g, h](x) I(x),
\end{aligned}
$$

for all $x \in[a, b]$ and

$$
\mid \frac{1}{b-a} \int_{a}^{b} f(x) g(x) h(x) d x-\frac{2}{3(b-a)^{2}} D[f, g, h]
$$




$$
\begin{aligned}
& -\frac{2}{3(b-a)} \int_{a}^{b}\left(x-\frac{a+b}{2}\right)(f(x) g(x) h(x))^{\prime} d x+\frac{1}{3(b-a)} \int_{a}^{b} L[f, g, h](x) d x \mid \\
\leq & \frac{1}{3(b-a)^{2}} \int_{a}^{b} B[f, g, h](x) I(x) d x,
\end{aligned}
$$

where

$$
I(x)=\int_{a}^{b}|p(x, t)|\left|t-\frac{a+b}{2}\right| d t,
$$

in which

$$
p(x, t)= \begin{cases}t-a & \text { if } t \in[a, x], \\ t-b & \text { if } t \in(x, b] .\end{cases}
$$

Remark 2. In the special case, when $h(x)=1$ and hence $h^{\prime}(x)=0, h^{\prime \prime}(x)=0$, it is easy to observe that, the inequalities obtained in (2.8) and (2.9) reduces to

$$
\begin{aligned}
& \mid f(x) g(x)-\frac{1}{b-a}\left\{g(x) \int_{a}^{b} f(t) d t+f(x) \int_{a}^{b} g(t) d t\right\} \\
& \quad-\left(x-\frac{a+b}{2}\right)(f(x) g(x))^{\prime}+\frac{1}{2}\left\{g(x) \frac{f(a)+f(b)}{2}+f(x) \frac{g(a)+g(b)}{2}\right\} \mid \\
& \leq \frac{1}{2(b-a)}\left\{|g(x)|\left\|f^{\prime \prime}\right\|_{\infty}+|f(x)|\left\|g^{\prime \prime}\right\|_{\infty}\right\} I(x),
\end{aligned}
$$

for all $x \in[a, b]$ and

$$
\begin{aligned}
\mid \frac{1}{b-a} & \int_{a}^{b} f(x) g(x) d x-\frac{2}{(b-a)^{2}}\left(\int_{a}^{b} f(x) d x\right)\left(\int_{a}^{b} g(x) d x\right) \\
& -\frac{1}{b-a} \int_{a}^{b}\left(x-\frac{a+b}{2}\right)(f(x) g(x))^{\prime} d x \\
& +\frac{1}{2(b-a)}\left\{\frac{f(a)+f(b)}{2} \int_{a}^{b} g(x) d x+\frac{g(a)+g(b)}{2} \int_{a}^{b} f(x) d x\right\} \mid \\
\leq & \frac{1}{2(b-a)^{2}} \int_{a}^{b}\left\{|g(x)|\left\|f^{\prime \prime}\right\|_{\infty}+|f(x)|\left\|g^{\prime \prime}\right\|_{\infty}\right\} I(x) d x .
\end{aligned}
$$

Further, by taking $g(x)=1$ and hence $g^{\prime}(x)=0, g^{\prime \prime}(x)=0$ in (2.12) and by simple caculations we get

$$
\begin{aligned}
& \left|f(x)-\frac{2}{b-a} \int_{a}^{b} f(t) d t-2\left(x-\frac{a+b}{2}\right) f^{\prime}(x)+\frac{f(a)+f(b)}{2}\right| \\
& \leq \frac{1}{b-a}\left\|f^{\prime \prime}\right\|_{\infty} I(x),
\end{aligned}
$$


for all $x \in[a, b]$. By rewriting (2.14), it is easy to observe that, we get the inequality established by Dragomir and Sofo in [3] .

Theorem 3. Let $f, g, h:[a, b] \rightarrow R$ be continuous on $[a, b]$ and twice differentiable on $(a, b)$ whose second derivatives $f^{\prime \prime}, g^{\prime \prime}, h^{\prime \prime}:(a, b) \rightarrow R$ are bounded on $(a, b)$. Then

$$
\begin{aligned}
& \left|f(x) g(x) h(x)-\frac{1}{3(b-a)} A[f, g, h](x)-\frac{1}{3}\left(x-\frac{a+b}{2}\right) M[f, g, h](x)\right| \\
& \quad \leq \frac{1}{3(b-a)^{2}} B[f, g, h](x) H(x),
\end{aligned}
$$

for all $x \in[a, b]$ and

$$
\begin{gathered}
\mid \frac{1}{b-a} \int_{a}^{b} f(x) g(x) h(x) d x-\frac{1}{3(b-a)^{2}} D[f, g, h] \\
\quad-\frac{1}{3(b-a)} \int_{a}^{b}\left(x-\frac{a+b}{2}\right) M[f, g, h](x) d x \mid \\
\leq \frac{1}{3(b-a)^{3}} \int_{a}^{b} B[f, g, h](x) H(x) d x
\end{gathered}
$$

where

$$
H(x)=\int_{a}^{b} \int_{a}^{b}|p(x, t)||p(t, s)| d s d t,
$$

in which $p(x, t)$ is given by $(2.11)$.

Remark 3. Taking $h(x)=1$ and hence $h^{\prime}(x)=0, h^{\prime \prime}(x)=0$ in Theorem 3 and by simple calculations, it is easy to see that the inequalities (2.15) and (2.16) reduces to

$$
\begin{aligned}
\mid f(x) g(x)-\frac{1}{2(b-a)}\left\{g(x) \int_{a}^{b} f(t) d t+f(x) \int_{a}^{b} g(t) d t\right\} \\
\quad-\frac{1}{2}\left(x-\frac{a+b}{2}\right)\left\{g(x) \frac{f(b)-f(a)}{b-a}+f(x) \frac{g(b)-g(a)}{b-a}\right\} \mid \\
\leq \frac{1}{2(b-a)^{2}}\left\{|g(x)|\left\|f^{\prime \prime}\right\|_{\infty}+|f(x)|\left\|g^{\prime \prime}\right\|_{\infty}\right\} H(x),
\end{aligned}
$$

for all $x \in[a, b]$ and

$$
\begin{aligned}
& \mid \frac{1}{b-a} \int_{a}^{b} f(x) g(x) d x-\frac{1}{(b-a)^{2}}\left(\int_{a}^{b} f(x) d x\right)\left(\int_{a}^{b} g(x) d x\right) \\
& \quad-\frac{1}{2(b-a)} \int_{a}^{b}\left(x-\frac{a+b}{2}\right)\left\{g(x) \frac{f(b)-f(a)}{b-a}+f(x) \frac{g(b)-g(a)}{b-a}\right\} \mid \\
& \quad \leq \frac{1}{2(b-a)^{3}} \int_{a}^{b}\left\{|g(x)|\left\|f^{\prime \prime}\right\|_{\infty}+|f(x)|\left\|g^{\prime \prime}\right\|_{\infty}\right\} H(x) d x .
\end{aligned}
$$


Further, by taking $g(x)=1$ and hence $g^{\prime}(x)=0, g^{\prime \prime}(x)=0$ in (2.18) and by simple calculations, we get the following inequality established by Dragomir and Barnett in 2]

$$
\left|f(x)-\frac{1}{b-a} \int_{a}^{b} f(t) d t-\left(x-\frac{a+b}{2}\right) \frac{f(b)-f(a)}{b-a}\right| \leq \frac{1}{(b-a)^{2}}\left\|f^{\prime \prime}\right\|_{\infty} H(x),
$$

for all $x \in[a, b]$.

\section{Proof of Theorem 1}

From the hypotheses, the following identities hold(see [1, p.35]):

$$
\begin{aligned}
& f(x)=\frac{1}{b-a} \int_{a}^{b} f(t) d t+\left(x-\frac{a+b}{2}\right) f^{\prime}(x)-\frac{1}{b-a} \int_{a}^{b} k(x, t) f^{\prime \prime}(t) d t, \\
& g(x)=\frac{1}{b-a} \int_{a}^{b} g(t) d t+\left(x-\frac{a+b}{2}\right) g^{\prime}(x)-\frac{1}{b-a} \int_{a}^{b} k(x, t) g^{\prime \prime}(t) d t, \\
& h(x)=\frac{1}{b-a} \int_{a}^{b} h(t) d t+\left(x-\frac{a+b}{2}\right) h^{\prime}(x)-\frac{1}{b-a} \int_{a}^{b} k(x, t) h^{\prime \prime}(t) d t,
\end{aligned}
$$

for $x \in[a, b]$, where $k(x, t)$ is given by (2.4). Multiplying both sides of (3.1), (3.2) and (3.3) by $g(x) h(x), h(x) f(x)$ and $f(x) g(x)$ respectively, adding the resulting identities and rewriting we have

$$
\begin{aligned}
f(x) & g(x) h(x)-\frac{1}{3(b-a)} A[f, g, h](x)-\frac{1}{3}\left(x-\frac{a+b}{2}\right)(f(x) g(x) h(x))^{\prime} \\
= & -\frac{1}{3(b-a)}\left\{g(x) h(x) \int_{a}^{b} k(x, t) f^{\prime \prime}(t) d t+h(x) f(x) \int_{a}^{b} k(x, t) g^{\prime \prime}(t) d t\right. \\
& \left.+f(x) g(x) \int_{a}^{b} k(x, t) h^{\prime \prime}(t) d t\right\} .
\end{aligned}
$$

From (3.4) and using the properties of modulus we have

$$
\begin{aligned}
\mid f(x) & g(x) h(x)-\frac{1}{3(b-a)} A[f, g, h](x)-\frac{1}{3}\left(x-\frac{a+b}{2}\right)(f(x) g(x) h(x))^{\prime} \mid \\
\leq & \frac{1}{3(b-a)}\left\{|g(x)||h(x)| \int_{a}^{b}|k(x, t)|\left|f^{\prime \prime}(t)\right| d t+|h(x)||f(x)| \int_{a}^{b}|k(x, t)|\left|g^{\prime \prime}(t)\right| d t\right. \\
& \left.+|f(x)||g(x)| \int_{a}^{b}|k(x, t)|\left|h^{\prime \prime}(t)\right| d t\right\} \\
\leq & \frac{1}{3(b-a)}\left\{|g(x)||h(x)|\left\|f^{\prime \prime}\right\|_{\infty}+|h(x)||f(x)|\left\|g^{\prime \prime}\right\|_{\infty}\right. \\
& \left.+|f(x)||g(x)|\left\|h^{\prime \prime}\right\|_{\infty}\right\} \int_{a}^{b}|k(x, t)| d t
\end{aligned}
$$




$$
=\frac{1}{3(b-a)} B[f, g, h](x) E(x) .
$$

This is the required inequality in (2.1).

Integrating both sides of (3.4) with respect to $x$ over $[a, b]$ and rewriting we have

$$
\begin{aligned}
\frac{1}{b-a} & \int_{a}^{b} f(x) g(x) h(x) d x-\frac{1}{3(b-a)^{2}} D[f, g, h] \\
& -\frac{1}{3(b-a)} \int_{a}^{b}\left(x-\frac{a+b}{2}\right)(f(x) g(x) h(x))^{\prime} d x \\
= & -\frac{1}{3(b-a)^{2}} \int_{a}^{b}\left\{g(x) h(x) \int_{a}^{b} k(x, t) f^{\prime \prime}(t) d t\right. \\
& \left.+h(x) f(x) \int_{a}^{b} k(x, t) g^{\prime \prime}(t) d t+f(x) g(x) \int_{a}^{b} k(x, t) h^{\prime \prime}(t) d t\right\} d x .
\end{aligned}
$$

From (3.5) and using the properties of modulus we get the required inequality in (2.2). The proof is complete.

\section{Proof of Theorem 2}

From the hypotheses, we have the following dientities(see [3, p.232]):

$$
\begin{aligned}
f(x)= & \frac{2}{b-a} \int_{a}^{b} f(t) d t+2\left(x-\frac{a+b}{2}\right) f^{\prime}(x) \\
& -\frac{f(a)+f(b)}{2}-\frac{1}{b-a} \int_{a}^{b} p(x, t)\left(t-\frac{a+b}{2}\right) f^{\prime \prime}(t) d t, \\
g(x)= & \frac{2}{b-a} \int_{a}^{b} g(t) d t+2\left(x-\frac{a+b}{2}\right) g^{\prime}(x) \\
& -\frac{g(a)+g(b)}{2}-\frac{1}{b-a} \int_{a}^{b} p(x, t)\left(t-\frac{a+b}{2}\right) g^{\prime \prime}(t) d t, \\
h(x)= & \frac{2}{b-a} \int_{a}^{b} h(t) d t+2\left(x-\frac{a+b}{2}\right) h^{\prime}(x) \\
& -\frac{h(a)+h(b)}{2}-\frac{1}{b-a} \int_{a}^{b} p(x, t)\left(t-\frac{a+b}{2}\right) h^{\prime \prime}(t) d t,
\end{aligned}
$$

for $x \in[a, b]$, where $p(x, t)$ is given by (2.11). Multiplying both sides of (4.1), (4.2) and (4.3) by $g(x) h(x), h(x) f(x)$, and $f(x) g(x)$ respectively, adding the resulting identities and rewriting we have

$$
f(x) g(x) h(x)=\frac{2}{3(b-a)} A[f, g, h](x)+\frac{2}{3}\left(x-\frac{a+b}{2}\right)(f(x) g(x) h(x))^{\prime}-\frac{1}{3} L[f, g, h](x)
$$




$$
\begin{aligned}
& -\frac{1}{3(b-a)}\left\{g(x) h(x) \int_{a}^{b} p(x, t)\left(t-\frac{a+b}{2}\right) f^{\prime \prime}(t) d t\right. \\
& +h(x) f(x) \int_{a}^{b} p(x, t)\left(t-\frac{a+b}{2}\right) g^{\prime \prime}(t) d t \\
& \left.+f(x) g(x) \int_{a}^{b} p(x, t)\left(t-\frac{a+b}{2}\right) h^{\prime \prime}(t) d t\right\} .
\end{aligned}
$$

From (4.4) and using the properties of modulus we have

$$
\begin{aligned}
\mid f(x) & g(x) h(x)-\frac{2}{3(b-a)} A[f, g, h](x) \\
& -\frac{2}{3}\left(x-\frac{a+b}{2}\right)(f(x) g(x) h(x))^{\prime}+\frac{1}{3} L[f, g, h](x) \mid \\
\leq & \frac{1}{3(b-a)}\left\{|g(x)||h(x)| \int_{a}^{b}|p(x, t)|\left|t-\frac{a+b}{2}\right|\left|f^{\prime \prime}(t)\right| d t\right. \\
& +|h(x)||f(x)| \int_{a}^{b}|p(x, t)|\left|t-\frac{a+b}{2}\right|\left|g^{\prime \prime}(t)\right| d t \\
& \left.+|f(x)||g(x)| \int_{a}^{b}|p(x, t)|\left|t-\frac{a+b}{2}\right|\left|h^{\prime \prime}(t)\right| d t\right\} \\
\leq & \frac{1}{3(b-a)}\left\{|g(x)||h(x)|\left\|f^{\prime \prime}\right\|_{\infty}+|h(x)||f(x)|\left\|g^{\prime \prime}\right\|_{\infty}\right. \\
& \left.+|f(x)||g(x)|\left\|h^{\prime \prime}\right\|_{\infty}\right\} \int_{a}^{b}|p(x, t)|\left|t-\frac{a+b}{2}\right| d t \\
= & \frac{1}{3(b-a)} B[f, g, h](x) I(x) .
\end{aligned}
$$

This proves the inequality (2.8).

Integrating both sides of (4.4) with respect to $x$ over $[a, b]$ and rewriting we have

$$
\begin{aligned}
\frac{1}{b-a} & \int_{a}^{b} f(x) g(x) h(x) d x-\frac{2}{3(b-a)^{2}} D[f, g, h] \\
& -\frac{2}{3(b-a)} \int_{a}^{b}\left(x-\frac{a+b}{2}\right)(f(x) g(x) h(x))^{\prime} d x \\
& +\frac{1}{3(b-a)} \int_{a}^{b} L[f, g, h](x) d x \\
= & -\frac{1}{3(b-a)^{2}} \int_{a}^{b}\left\{g(x) h(x) \int_{a}^{b} p(x, t)\left(t-\frac{a+b}{2}\right) f^{\prime \prime}(t) d t\right. \\
& +h(x) f(x) \int_{a}^{b} p(x, t)\left(t-\frac{a+b}{2}\right) g^{\prime \prime}(t) d t
\end{aligned}
$$




$$
\left.+f(x) g(x) \int_{a}^{b} p(x, t)\left(t-\frac{a+b}{2}\right) h^{\prime \prime}(t) d t\right\} d x .
$$

From (4.5) and using the properties of modulus, we get the desired inequality in (2.9). The proof is complete.

\section{Proof of Theorem 3}

From the hypotheses, the following identities hold(see [2,p.71]):

$$
\begin{aligned}
f(x)= & \frac{1}{b-a} \int_{a}^{b} f(t) d t+\frac{f(b)-f(a)}{b-a}\left(x-\frac{a+b}{2}\right) \\
& +\frac{1}{(b-a)^{2}} \int_{a}^{b} \int_{a}^{b} p(x, t) p(t, s) f^{\prime \prime}(s) d s d t \\
g(x)= & \frac{1}{b-a} \int_{a}^{b} g(t) d t+\frac{g(b)-g(a)}{b-a}\left(x-\frac{a+b}{2}\right) \\
& +\frac{1}{(b-a)^{2}} \int_{a}^{b} \int_{a}^{b} p(x, t) p(t, s) g^{\prime \prime}(s) d s d t \\
h(x)= & \frac{1}{b-a} \int_{a}^{b} h(t) d t+\frac{h(b)-h(a)}{b-a}\left(x-\frac{a+b}{2}\right) \\
& +\frac{1}{(b-a)^{2}} \int_{a}^{b} \int_{a}^{b} p(x, t) p(t, s) h^{\prime \prime}(s) d s d t
\end{aligned}
$$

for $x \in[a, b]$, where $p(x, t)$ is given by (2.11). The rest of the proof can be completed by following the similar arguments as used in the proof of Theorems 1 and 2 with suitable modifications. Here we omit the details.

Remark 4. We note that, in [1, p.35], [3, p.231], [2, p.70] the authors have evaluted the integrals in $(2.3),(2.10),(2.17)$. We also note that one can very easily obtain the bounds on the right hand sides in $(2.1),(2.2),(2,8),(2.9),(2.15),(2.16)$ when $f^{\prime \prime}, g^{\prime \prime}, h^{\prime \prime}$ all belongs to $L_{p}[a, b]$ for $p>1, \frac{1}{p}+\frac{1}{q}=1$ or $L_{1}[a, b]$. The precise formulations of such results are very close to those given in Theorems 1-3 with suitable changes. We do not discuss it here.

\section{References}

[1] P. Cerone, S. S. Dragomir and J. Roumeliotis, An inequality of Ostrowski type for mappings whose second derivatives are bounded and applications, RGMIA Research Report Collection, Victoria University of Techonology 1 (1998), 33-39.

[2] S. S. Dragomir and N. S. Barnett, An Ostrowski type inequality for mappings whose second derivatives are bounded and applications, RGMIA Research Report Collection, Victoria University of Techonology 1 (1998), 69-77. 
[3] S. S. Dragomir and Sofo, An integral inequality for twice differentiable mappings and applications, RGMIA Research Report Collection, Victoria University of Techonology 2 (1999), 229-240.

[4] S. S. Dragomir and T. M. Rassias(Eds.), Ostrowski type inequalities and application in numerical integration, Kluwer Academic Publishers, Dordrecht, 2002.

[5] G. Grüss, Über das maxumum des absoluten Betrages von

$$
\frac{1}{b-a} \int_{a}^{b} f(x) g(x) d x-\frac{1}{(b-a)^{2}} \int_{a}^{b} f(x) d x \int_{a}^{b} g(x) d x
$$

Math. Z. 39(1935), 215-226.

[6] D. S. Mitrinović, J. E. Pečarić and A. M. Fink, Classical and new inequalities in analysis, Kluwer Academic Publishers, Dordrecht, 1993.

[7] D. S. Mitrinović, J. E. Pečarić and A. M. Fink, Inequalities for functions and their integrals and derivatives, Kluwer Academic Publishers, Dordrecht, 1994.

[8] A. M. Ostrowski, Über die Absolutabweichung einer differentiebaren Funktion van ihrem Integralmittelwert, Comment Math. Helv. 10(1938), 226-227.

[9] B. G. Pachpatte, On Trapzoid and Grüss like integral inequalities, Tamkang J. Math. 34(2003), 365-369.

[10] B. G. Pachpatte, New inequalities of Ostrowski type for twice differentiable mappings, Tamkang J. Math. 35(2004), 219-226.

57 Shri Niketan Colony, Near Abhinay Talkies, Aurangabad 431001 (Maharashtra) India.

E-mail: bgpachpatte@gmail.com 